\title{
Opinion
}

\section{Workstyle reform for Japanese doctors}

\author{
Akizumi Tsutsumi (i) \\ Department of Public Health, Kitasato University School of Medicine, Kanagawa, Japan
}

\begin{abstract}
Workstyle reform for Japanese doctors is a priority of Japanese labor policy. Factors influencing this include the low birthrate and longevity of the population and the long working hours experienced by Japanese workers. Long working hours imperil the health of doctors and create discord between their work and other life roles. The Japanese government enacted measures to promote workstyle reform for doctors, including a provision that capped legal overtime work. The limit was set to sustain healthcare services in the community. However, the allowed level of overtime is substantially higher than the so-called "line of karoshi" at which point worker compensation for work-related medical disorders is approved. Despite limited research, several measures can be considered to reduce health risks of overworked doctors, such as recommending psychological detachment from clinical work and maintaining work-life balance. Doctors should realize that self-care is a professional imperative. Organizational efforts from public administration entities or hospitals are required to secure the health of doctors. The number of surgeons and obstetricians has not recently increased. Gender role stereotyping has encouraged male Japanese doctors to work long hours and makes it difficult for female doctors to continue their professional life after childbirth. Without reforming the workstyle and protecting the health of doctors, younger workers, particularly women, are liable to avoid entering medical professions. To ensure the provision of good healthcare, it is necessary to change traditional values and improve the work environment. Academics in occupational fields should produce evidence that will help improve Japanese labor policies.
\end{abstract}

Keywords: burnout, gender role stereotyping, harmonizing work and life, karoshi, long working hours, work-life balance

(Received April 24, 2020; Accepted May 8, 2020; Published online in J-STAGE June 15, 2020)

\section{Japanese demographic shift in the near future and workstyle reform - regulations on working hours}

During the 10 years from 2015 to 2025 , the Japanese population will decrease by 4.6 million. The population aged 65 years and older will increase by 2.9 million, whereas the productive-age population will decrease by 5.6 million $^{1)}$. As the Japanese social insurance system depends on the transfer of money from the working generation to those who are retired, the increasing aged population and the decreasing working population has caused

Correspondence

Akizumi Tsutsumi: Department of Public Health, Kitasato University School of Medicine, Kanagawa, Japan

E-mail: akizumi@kitasato-u.ac.jp financial difficulty ${ }^{2)}$. Serious matters must be addressed to maintain the workforce, such as improving the work environment for older people and women and a greater acceptance of foreign workers. Another aspect is particularly related to medical professionals. The elderly population will reach 36 million in 2020, and additional medical professionals are needed to manage a high-mortality-rate society.

Another related issue is the presence of long working hours and overwork. Overall, there is a declining trend in actual working hours per year for Japanese workers. However, the proportion of part-time workers has been increasing, comprising 30 percent of the total Japanese workforce. Assessing the trend of total actual working hours per year separately for general workers and parttime workers shows that the total actual working hours of general workers has remained high (on average 2,010 
hours per year in 2018) $)^{3)}$. In addition, Japanese workers tend to not use their annual paid vacation entitlement.

A total of 1,732 claims were submitted requesting worker compensation for work-related mental disorders in 2017, of which 506 claims for mental disorders were approved for compensation, and 98 cases were for suicide $^{4)}$. The number of claims for mental disorders increased more than tenfold during the last two decades. Long working hours and overwork are believed to be behind this phenomenon. The Japanese government has instituted several measures to address this situation. In 2006, the government amended the industrial safety and health law and introduced the system of the Doctor's Interview of Workers with Long Working Hours. A law regarding preventive measures against karoshi (death due to overwork) was enacted in 2014. An assessment of the number of claims requesting compensation does not reveal any effect of the introduction so far.

In 2018, the government instituted a set of measures to promote Japanese workstyle reform, which included an amendment to the Labor Standards Act. The amended act includes new regulations on working hours and the introduction of a work-interval system (minimum daily rest periods). Prior to this change, there was no official limit on overtime work in Japan. The amendments to the Japan Labor Standards Act included provisions that capped legal overtime at 45 hours per month and 360 hours per year for full-time workers. The provisions permitted an extension of up to 100 hours per month and 720 hours per year for busy periods for a maximum of 6 months per year. This regulation has been in effect since April 2019 for large enterprises. There are some exceptions, including a 1-year delay in implementation for small- and medium-sized enterprises, and a 5-year delay for occupations for which it is difficult to implement the regulation immediately, such as drivers, construction workers, and medical doctors.

\section{The experience of doctors}

Japanese doctors work very long hours. Over 40 percent of Japanese hospital doctors work more than 60 hours per week ${ }^{5)}$. Various factors contribute to the long working hours of doctors, such as doctor shortages and an uneven distribution of doctors between regions ${ }^{6}$ and specialties $^{7,8)}$, and a lack of task sharing ${ }^{9)}$. There are health risks for doctors because of overwork (karoshi and burnout $)^{10)}$, contributing to the issue of medical care security $^{11)}$.

A recent meta-analysis based on pooled data from European cohort studies, which included unpublished research, provided robust evidence related to this topic ${ }^{10)}$. The analysis showed elevated risks for cardiovascular diseases among those who worked long hours (55 or more hours per week) compared with those working stan- dard hours (35-40 hours per week). The authors found an increased risk of incident coronary heart disease (relative risk [RR] 1.13; 95\% confidence interval [CI], 1.02-1.26) and incident stroke (RR 1.33; 95\% CI, 1.11-1.61). As the prevalence of long working hours is high among Japanese doctors, the impact of long working hours on cardiovascular diseases (e.g., coronary heart disease and stroke) cannot be negligible. Given that the prevalence of Japanese doctors with long working hours (60 or more hours per week) was $40 \%$, more than $15 \%$ of cardiovascular disease cases are estimated to be attributable to long working hours. Burnout is another considerable health issue among doctors ${ }^{12}$. Long working hours are closely related with physician burnout ${ }^{13)}$, and physician burnout may jeopardize patient care ${ }^{14}$. Furthermore, the cost related to clinical and organizational outcomes is enormous $^{15}$.

\section{Work-life balance and gender role stereotyping}

Work-life balance has come under the spotlight in a special context of Japanese workstyle reform. Japan has the lowest proportion of female doctors among the Organisation for Economic Cooperation and Development (OECD) countries. The average proportion of female doctors in OECD countries was 46.5\% in 2015. The proportion was the lowest in Japan, at $20.3 \%{ }^{16}$. The trend of female doctors' participation in the labor force by age group shows an M-curve, as many female doctors quit their jobs upon marriage or childbirth. This pattern is hardly seen in the other OECD countries.

Hard work is a virtue in Japan, and the male-breadwinner model deeply permeated 20th-century Japanese society. Such gender role stereotyping has pressured male Japanese doctors to devote themselves full time to their practice and work long hours, leaving all other family life roles to their female partners and sacrificing their private lives. Stereotyping forces female doctors to do household chores in addition to their professional tasks, making it difficult to continue with professional life ${ }^{17)}$. Importantly, these circumstances have forced many female doctors to quit their jobs; thus, they cannot utilize their professional ability.

\section{Working limits for doctors}

Excessive work demands not only affect doctors' health, but they also impact the outcomes of patients who should benefit from the doctors' expertise. Working limits for doctors have been regulated based on a discussion regarding medical care security in Western societies. In Japan, the regulation was enacted by placing importance on securing medical services. 
In the United States, inhumane working conditions of residents gained prominent attention during an inspection of a medical accident where an 18-year-old girl died because of a lethal drug interaction. In the early $2000 \mathrm{~s}$, accumulating data showed increased risks of accidents and/or medical errors due to extended work shifts or extended-duration shifts ${ }^{18)}$. Accordingly, in 2003, the Accreditation Council for Graduate Medical Education (ACGME) implemented rules limiting residents to an 80-hour workweek. In 2011, ACGME implemented additional rules, including one stating that intern shifts were not to exceed 16 hours. After the implementation of the resident working hour restrictions, there was a report that burnout indices were lowered among internal medicine residents of a university health center, though residents reported attending fewer educational conferences and less satisfaction ${ }^{19)}$. Recently, however, a nation-wide, clusterrandomized trial involving 117 general surgery residency programs in the United States revealed that compared with the ACGME standard working hour policies, there were no inferior patient outcomes for flexible and lessrestrictive working hour policies for surgical residents. There were no significant differences in resident satisfaction regarding overall well-being and education quality between the two policies ${ }^{11)}$. The same type of randomized controlled trial among internal medicine residency programs found no difference in the proportion of time that medical interns spent on direct patient care and education between programs with standard working hour policies and programs with more flexible policies ${ }^{20)}$. ACGME has since eased their regulations to allow resident shift lengths of 24 hours.

The European Union (EU) has set a different level of regulation. The European Working Time Directive requires a maximum working week of 48 hours and establishes rest periods; this regulation is applicable to all occupations across the EU (however, it is not strictly enforced, and junior doctors may opt-out in the United Kingdom). A systematic review of 11 studies of high or intermediate quality found that long working hours per day or very long hours per week were associated with percutaneous injuries and road traffic accidents ${ }^{21}$. Doctors were surveyed 10 years after the directive was introduced. Generally, senior doctors agreed the directive was good for doctors' work-life balance, while they thought it had a negative impact on managing patient care and on junior doctors' training opportunities ${ }^{22)}$.

In the amendments to Japan's Labor Standards Act, three levels have been set to cap the overtime hours of doctors working in medical institutions. For doctors in general, the total overtime hours have been set at 960 hours per year and less than 100 hours per month. The total working hours include hours worked on off-duty days. For doctors working at certain medical institutions that provide crucial medical services to the local com- munity, such as emergency treatment, perinatal care, and advanced cancer treatment, the overtime regulation permits an extension of up to 1,860 hours per year and 100 hours per month. The figures were set on the grounds that such levels of working hours are required to sustain the services provided at these medical institutions. The same level of overtime has been set for residents who are focusing on their basic skills and abilities within a residency program and for trainees who practice at specified medical institutions and who are training in specialized knowledge and skills. This regulation will be enacted in 2024 and will be in place through 2035.

\section{How to protect doctors' health}

Although overtime work is limited, the upper limit is immensely above the so-called "line of karoshi" where worker compensation for work-related medical disorders will be approved (more than 80 hours of overtime per month). The government has formed a panel of experts to discuss how to protect doctors' health. Doctors who are predicted to work overtime beyond the above limit must see a doctor for a medical check. Although there is no evidence of the effectiveness of these medical interviews, the following points should be considered.

First, the focus of these measurements should not only consider restrictions in working time - they should also comprise medical advice and a health assessment. Regarding the assessment, stressors other than long working hours should be assessed (Table 1). There is robust evidence showing that job characteristics assessed by occupational stress models, such as the job demandcontrol model and the effort-reward imbalance model, predict cardiovascular diseases ${ }^{23,24)}$ and mental illness, including depression ${ }^{25)}$ and suicide ${ }^{26)}$. An assessment of such job characteristics will provide hints for measures to take to reduce stressful work conditions.

Doctors with severe or unusual symptoms (Table 2) may be advised to discuss restrictions on work with the hospital administrators or be referred to the appropriate professional medical organization. Burnout should be assessed among stressed doctors because the risk of burnout among doctors is high and the consequent outcome is

Table 1. Adverse job characteristics other than working hours Irregular work (emergency operation, sudden changes in the patient's condition, etc.

Frequent business trips (time lag, etc.)

Night shifts

Human relationships

Tasks with mental strain

Long commuting times

High job demand/low control/low support

Effort-reward imbalance 
Table 2. Symptoms that may trigger work restriction advice or involvement of professional medical organizations

Severe autonomic nervous symptoms (vertigo, dizziness, nausea, psychroesthesia, low fever) and strong fatigue

Strong subjective symptoms of chronic exhaustion, loss of work motivation (burnout)

Severe depressive state and anxiety

Severe sleep disorder that obstructs daily work

Suicidal ideation

significant ${ }^{12)}$. Furthermore, the suicide rate among doctors is high. Interviewers should be cognizant of the onset of work-related diseases, such as cardiovascular disease, mental illness (especially depression), sleep disorders, and suicidal ideation. Several easy-to-use instruments to screen depression at occupational fields have been introduced (e.g., the Brief Structured Interview for Depression $)^{27)}$. Any subsequent measures, such as referral to a specialist or follow-up observation, must be carried out after screening ${ }^{28}$.

The health assessment may take into account individual demographic factors, including age and sex, because health problems induced by overwork can be increased or decreased according to the demographic characteristics of doctors. Regarding the gender differences of psychiatric diseases and suicide, for which there is a high risk among doctors, these conditions show a particularly high incident level among female doctors ${ }^{29)}$. Regarding cardiovascular diseases, it is recommended to assess health risks among doctors using the assessment of the Framingham risk $\operatorname{score}^{30)}$. A risk assessment chart that incorporates long working hours and work stress in addition to individual factors is available as a reference ${ }^{311}$.

There is no specific medical advice for doctors who work long hours. Not only time restriction but also comprehensive risk reduction is needed. It is well-known that doctors are reluctant to recognize that they are $\mathrm{ill}^{32)}$. Doctors must realize that from a professional perspective, their health risks impact their individual issues, as well as the care they give to patients; therefore, they must get sufficient rest and stay healthy. Regarding sleep duration, it is recommended to get at least 6 hours of sleep per night ${ }^{33}$. General recommendations for good quality sleep can be given, such as avoiding caffeine and smoking, engaging in adequate physical exercise, and avoiding screen-time before going to bed. Consuming alcohol before bed should also be avoided because this habit is associated with an increased risk of cerebral bleeding death related to fewer sleeping hours ${ }^{34)}$.

Complete disconnection from work (psychological detachment) is associated with good recovery ${ }^{35}$. Concrete advice may include coping behaviors that clear out one's mind by engaging in physical fitness and/or hobbies. Although this coping strategy may not be effective for some workers, it may be a good coping strategy for medical professionals who are experiencing a substantial emotional load.

Satisfaction with vacations, hobby activities, and family get-togethers were found to be related to lower levels of fatigue among administrative workers and home business owners who reported long working hours that were comparable to those reported by doctors ${ }^{36}$. An unfavorable work-life balance was reported to be a risk factor for mental illness among doctors.

There is much evidence showing that favorable health behaviors can increase one's stress tolerance help to prevent cardiovascular diseases. In addition to addressing sleep and rest, the medical advice should encourage doctors to eat fruits and vegetables, engage in physical fitness ${ }^{37,38)}$, and properly manage their blood pressure and body weight. It should be recommended that they quit smoking and rest when tired.

It has been suggested that shorter intervals away from work lead to shorter sleeping times and poor sleep quality $^{39}$. One report showed that staying home while ill reduced the risk of serious coronary events ${ }^{40)}$. Necessary work restrictions, including compensated rest times, should be put into effect.

Prolonging the time away from work each day was shown to be effective for reducing the health risks of doctors $^{39)}$, and there was a high recovery effect as a result of doing activities unrelated to work ${ }^{35)}$. Enabling doctors to disconnect from work includes freeing them from on-call jobs and strict shift controls. Regulations, such as standardized absences from work, are not necessarily required, as the degree of fatigue differs among doctors. However, a viable healthcare system requires that doctors can refrain from work for a time if the need arises. A backup system that enables restrictions on work and allows doctors to stay home when they are ill (i.e., doctor pools) is necessary. Otherwise, the public administration must ask citizens to understand the limited medical services.

\section{Summary}

The Japanese government has capped the legal overtime of doctors, but evidence shows that this level still poses risks to doctors' health. The virtue of working hard has sustained Japanese healthcare, which is threatened by a shrinking workforce and an aging population. There is also a generation gap in attitudes surrounding work and work preferences. Veteran doctors are more willing to work long hours, whereas younger doctors are not, which appears to reflect the uneven distribution of doctors between specialties ${ }^{7,8)}$ (young doctors tend to avoid selecting surgical specialties). Gender role stereotyping has pressured male Japanese doctors to work long hours and makes it very difficult for female doctors to continue 
their professional life after having children, resulting in the lowest proportion of female doctors among OECD countries. It is necessary to improve the work environment to ensure doctors' health and to harmonize the work and life roles of both male and female doctors. Otherwise, the younger labor force, and particularly women, will not enter the medical profession. It is necessary to change traditional values to sustain the provision of good healthcare. Academics in the occupational health fields should present factual evidence to support the implementation or modification of regulations.

\section{Acknowledgments}

This work was supported by the Work-related Diseases Clinical Research Grant 2017 (170401-02) and 2020 (200401-01), the Health, Labour and Welfare Sciences Research Grants (H30-meneki-ippan-001), and the Exploratory Committee on Ensuring Doctors' Health from the Ministry of Health, Labour and Welfare, Japan. A summary of this article was presented on November 2, 2019, at the 7th International Congress of Person-Centered Medicine-Promotion of Well-being: Challenges and Solutions. I thank Katherine Thieltges from Edanz Group (https://en-author-services.edanzgroup.com/) for editing a draft of this manuscript.

\section{Source of Funding}

The Work-related Diseases Clinical Research Grant 2017 (170401-02) and 2020 (200401-01), the Health, Labour and Welfare Sciences Research Grants (H30meneki-ippan-001), and the Exploratory Committee on Ensuring Doctors' Health from the Ministry of Health, Labour and Welfare, Japan.

\section{Conflict of Interest} none.

\section{ORCID}

\section{Akizumi Tsutsumi (D) https://orcid.org/0000-0003-0966-4869}

\section{References}

1. Current pupulation estimates as of October 1, 2017. http:// www.stat.go.jp/english/data/jinsui/2017np/index.html. Accessed December 12, 2019.

2. Matsuda S. Health policy in Japan — current situation and future challenges. Japan Med Assoc J. 2019; 2(1): 1-10.

3. Ministry of Health Labour and Welfare. 2018 White Paper on Prevention of Overwork Death Prevention Measures. 2019.

4. Labor Standards Bureau Compensation Division. Work accident compensation situation such as death from overwork in 2017. https://www.mhlw.go.jp/stf/newpage_00039.html. Published 2018. Accessed March 22, 2020.

5. Ministry of Health Labour and Welfare, Health Policy Bureau, Medical Institution Management Support Division. Material based on '2016 Research on doctors' actual working conditions and intentions of working'.

6. Kirino T. Shortage or Surplus of Doctors: the number of physicians and the origins of health care disparity. Tokyo: University of Tokyo Press; 2018.

7. Ide H, Yasunaga H, Kodama T, Koike S, Taketani Y, Imamura T. The dynamics of obstetricians and gynecologists in Japan: a retrospective cohort model using the nationwide survey of physicians data. J Obstet Gynaecol Res. 2009; 35(4): 761-766. [Medline] [CrossRef]

8. Ide H, Yasunaga H, Koike S, Kodama T, Igarashi T, Imamura T. Shortage of pediatricians in Japan: a longitudinal analysis using physicians' survey data. Pediatr Int. 2009; 51(5): 645-649. [Medline] [CrossRef]

9. The Japanese Medical Science Federation Work Environment Exploratory Committee. [Recommendation] Workstyle reform in Japanese doctors based on scientific evidence: for 'provision of high-quality and safety medical care' and 'securing health for hospital doctors'. 2018.

10. Kivimaki M, Jokela M, Nyberg ST, et al. Long working hours and risk of coronary heart disease and stroke: a systematic review and meta-analysis of published and unpublished data for 603,838 individuals. Lancet. 2015; 386(10005): 1739-1746.

11. Bilimoria KY, Chung JW, Hedges LV, et al. National clusterrandomized trial of duty-hour flexibility in surgical training. $N$ Engl J Med. 2016; 374(8): 713-727. [Medline] [CrossRef]

12. Rothenberger DA. Physician burnout and well-being: a systematic review and framework for action. Dis Colon Rectum. 2017; 60(6): 567-576. [Medline] [CrossRef]

13. Amoafo E, Hanbali N, Patel A, Singh P. What are the significant factors associated with burnout in doctors? Occup Med (Lond). 2015; 65(2): 117-121. [Medline] [CrossRef]

14. Panagioti M, Geraghty K, Johnson J, et al. Association between physician burnout and patient safety, professionalism, and patient satisfaction: a systematic review and meta-analysis. JAMA Intern Med. 2018; 178(10): 1317-1330. [Medline] [CrossRef]

15. Han S, Shanafelt TD, Sinsky CA, et al. Estimating the attributable cost of physician burnout in the United States. Ann Intern Med. 2019; 170(11): 784-790. [Medline] [CrossRef]

16. OECD. Share of female doctors, 2000 and 2015 (or nearest year). Paris: OECD Publishing; 2017.

17. Nagoshi S, (Chair, Exploratory Committee for Gender Equality, The Japanese Medical Science Federation). Agenda for work life balance from the perspective of female doctors.

18. Barger LK, Ayas NT, Cade BE, et al. Impact of extended-duration shifts on medical errors, adverse events, and attentional failures. PLoS Med. 2006; 3(12): e487. [Medline] [CrossRef]

19. Gopal R, Glasheen JJ, Miyoshi TJ, Prochazka AV. Burnout and internal medicine resident work-hour restrictions. Arch Intern Med. 2005; 165(22): 2595-2600. [Medline] [CrossRef]

20. Desai SV, Asch DA, Bellini LM, et al. iCOMPARE Research Group. Education outcomes in a duty-hour flexibility trial in internal medicine. $N$ Engl J Med. 2018; 378(16): 1494-1508. [Medline] [CrossRef] 
21. Rodriguez-Jareño MC, Demou E, Vargas-Prada S, et al. European Working Time Directive and doctors' health: a systematic review of the available epidemiological evidence. BMJ Open. 2014; 4(7): e004916. [Medline] [CrossRef]

22. Lambert TW, Smith F, Goldacre MJ. The impact of the European Working Time Directive 10 years on: views of the UK medical graduates of 2002 surveyed in 2013-2014. JRSM Open. 2016; 7(3): 2054270416632703. [Medline] [CrossRef]

23. Dragano N, Siegrist J, Nyberg ST, et al. IPD-Work consortium. Effort-reward imbalance at work and incident coronary heart disease: a multicohort study of 90,164 individuals. Epidemiology. 2017; 28(4): 619-626. [Medline] [CrossRef]

24. Kivimäki M, Nyberg ST, Batty GD, et al. IPD-Work Consortium. Job strain as a risk factor for coronary heart disease: a collaborative meta-analysis of individual participant data. Lancet. 2012; 380(9852): 1491-1497. [Medline] [CrossRef]

25. Madsen IEH, Nyberg ST, Magnusson Hanson LL, et al. IPDWork Consortium. Job strain as a risk factor for clinical depression: systematic review and meta-analysis with additional individual participant data. Psychol Med. 2017; 47(8): 1342-1356. [Medline] [CrossRef]

26. Milner A, Witt K, LaMontagne AD, Niedhammer I. Psychosocial job stressors and suicidality: a meta-analysis and systematic review. Occup Environ Med. 2018; 75(4): 245-253. [Medline] [CrossRef]

27. Hiro H. Brief Structured Interview for Depression, BSID. https://mental.m.u-tokyo.ac.jp/jstress/BSID.htm. Published 2004. Accessed March 22, 2020.

28. U.S. Preventive Services Task Force. Screening for depression: recommendations and rationale. Ann Intern Med. 2002; 136(10): 760-764. [Medline] [CrossRef]

29. Dutheil F, Aubert C, Pereira B, et al. Suicide among physicians and health-care workers: A systematic review and meta-analysis. PLoS One. 2019; 14(12): e0226361. [Medline] [CrossRef]

30. Nishimura K, Okamura T, Watanabe M, et al. Predicting coronary heart disease using risk factor categories for a Japanese urban population, and comparison with the Framingham Risk Score: the Suita Study. J Atheroscler Thromb. 2016; 23(9):
1138-1139. [Medline] [CrossRef]

31. Tsutsumi A. A health risk assessment chart for overworked employees. https://mental.m.u-tokyo.ac.jp/jstress/riskchart/index. htm. Published 2005. Accessed March 22, 2020.

32. Myers MF, Gabbard GO. The Physician as Patient: A Clinical Handbook for Mental Health Professionals. Arlington, Va: American Psychiatric Publishing; 2008.

33. Tanigawa T. Evidence based protection of doctors' health. Material for 11th expert committee on workstyle reform of Japanese doctors. Nov 92018.

34. Ikehara S, Iso H, Date C, et al. JACC Study Group. Association of sleep duration with mortality from cardiovascular disease and other causes for Japanese men and women: the JACC study. Sleep. 2009; 32(3): 295-301. [Medline] [CrossRef]

35. Sonnentag S. Recovery, work engagement, and proactive behavior: a new look at the interface between nonwork and work. J Appl Psychol. 2003; 88(3): 518-528. [Medline] [CrossRef]

36. Ministry of Health Labour and Welfare. 2017 White Paper on Prevention of Karoshi (Death caused by Overwork), etc. 2018.

37. Głąbska D, Guzek D, Groele B, Gutkowska K. Fruit and vegetable intake and mental health in adults: a systematic review. Nutrients. 2020; 12(1): E115. [Medline] [CrossRef]

38. Schuch FB, Vancampfort D, Firth J, et al. Physical activity and incident depression: a meta-analysis of prospective cohort studies. Am J Psychiatry. 2018; 175(7): 631-648. [Medline] [CrossRef]

39. Takahashi M. Comprehensive study for the current status and preventive strategies of overwork-related disorders, fiscal year 2015 (in Japanese). 2016.

40. Kivimäki M, Head J, Ferrie JE, et al. Working while ill as a risk factor for serious coronary events: the Whitehall II study. Am J Public Health. 2005; 95(1): 98-102. [Medline] [CrossRef]

How to cite this article: Tsutsumi A. Workstyle reform for Japanese doctors. Environ Occup Health Practice. 2020; 2: eohp.2020-0008-OP. https://doi.org/10.1539/eohp.2020-0008-OP 